\title{
Understanding of Clear Speech and Suggestions for Clinical Applications
}

\author{
Suyeon Shin ${ }^{1}$, Kyungju Lee ${ }^{1}$, In-Ki Jin² \\ 'Department of Speech Pathology and Audiology, Graduate School, Hallym University, Chuncheon, Korea \\ ${ }^{2}$ Division of Speech Pathology and Audiology, Research Institute of Audiology and Speech Pathology, College of Natural Sciences, \\ Hallym University, Chuncheon, Korea
}

\section{클리어스피치의 이해와 임상적 적용을 위한 제언}

신수연 ${ }^{1}$ 이경주 ${ }^{1}$ 진인기 ${ }^{2}$

한림대학교 일반대학원 언어병리청각학과', 한림대학교 자연과학대학 언어청각학부 · 청각언어연구소 ${ }^{2}$

\begin{abstract}
Clear speech is a talker-centered communication strategy using techniques such as accurate articulation, a slow rate of speech, and pauses. Several researchers have demonstrated that clear speech improves speech intelligibility performance compared to conversational speech, which is a way of speaking naturally. The purpose of this study was to review English-based clear speech. The current review included information for acoustic characteristics, improvement of speech intelligibility performance, and production methods for clear speech. This review also suggested considerations for the development of Korean-based clear speech. Although English-based clear speech is widely used as an effective communication strategy in several English-speaking countries, clear speech for Korean listeners has not been developed and applied. Thus, this review will provide some basic information to develop Korean-based clear speech.
\end{abstract}

Key Words: Speech intelligibility, Clear speech, Communication strategy.

Received: April 30, 2017 / Revised: June 4, 2017 / Accepted: June 6, 2017

Correspondence: In-Ki Jin, Division of Speech Pathology and Audiology, College of Natural Sciences, Hallym University, 1 Hallimdaehak-gil, Chuncheon 24252, Korea

Tel: +82-33-248-2221 / Fax: +82-33-256-3420 / E-mail: inkijin@hallym.ac.kr

\section{INTRODUCTION}

클리어스피치(clear speech)는 청자의 대화 이해도를 높이기 위한 어음 발성법으로서 말소리 산출 속도(speech rate)의 감 소, 음의 높낮이(pitch) 범위 확장, 중요 어휘의 강도(intensity) 증가를 통한 음향학적 조음 수정 전략을 의미한다(Smiljanic \& Bradlow, 2007).

난청자를 위한 의사소통 전략으로 제안되기 이전에 클리어스 피치는 군사용 음성송수신기기의 사용 시에 명료한 음성을 전 달하기 위한 발성법으로 사용되어 왔다(Snidecor et al., 1944). 주로 적용된 방법은 발성 속도를 늦추고 조음을 정확하게 하도 록 훈련하는 것이었으며, 최대 9\%까지 어음인지도(speech intelligibility)가 향상될 수 있다고 보고하였다(Tolhurst, 1957). 이후 여러 연구자들에 의하여 클리어스피치는 난청자의 어음 인지도 향상을 위한 의사소통 전략으로 제안되어 왔다(Caissie
\& Tranquilla, 2010; Picheny et al., 1985).

클리어스피치의 발성 방법은 연구자마다 다양한 의견으로 제시하고 있다. 일부 연구자들은 난청인 또는 외국인에게 이야 기하듯 발성하거나 시끄러운 환경에서 대화를 할 때처럼 발성 하는 방법이라고 제시하였는데(Godoy et al., 2014; Picheny et al., 1985; Smiljanic \& Bradlow, 2007), 특히, Bradlow \& Bent (2002)는 클리어스피치와 일반 발성법(conversational speech) 간의 차이는 발음에 들이는 노력의 차이라고 언급하였다. 이는 클리어스피치로 발성할 때 조음의 정확도를 높이기 위하여 또 렷한 목소리로 ‘또박또박' 발성하는 것을 의미한다. Picheny et al.(1986)은 클리어스피치의 발성 특징은 일반 발성법보다 발성 속도를 늦추고 정확하게 발음하며, 중요 단어를 강조하고 절 사 이에 휴지기(pause)를 가진다고 보고하였다. 또 다른 연구들에 서는 클리어스피치의 특징은 말끝을 흐리지 않고 조금 더 천천 히 이야기하며 가능한 발음을 정확하게 하고 동사, 명사, 형용 
사 등 핵심 단어를 강조하고 목소리를 생동감(lively) 있게 유지 하도록 발성해야 한다고 제안하였다(Caissie et al., 2005; Kricos, 2006; Moon \& Lindblom, 1994; Picheny et al., 1986).

클리어스피치 사용에 따른 가장 큰 효과는 어음인지도의 향 상이다. 선행 연구에서 클리어스피치는 일반 발성법의 사용 시 와 비교하였을 때, 건청인과 난청인 모두에서 어음인지도의 향 상이 두드러진다고 보고하였다(Gagné et al., 1994; Krause \& Braida, 2004; Liu et al., 2004; Picheny et al., 1986; Schum, 1996). 또한 클리어스피치는 학습장애가 있는 아동의 어음인지 도 향상에 효과가 있으며(Bradlow et al., 2003), 클리어스피치 사용 시에 비원어민이나 원어민 모두에게서 어음인지도 수행력 이 증가한다고 보고하였다(Bilbao, 2013; Smiljanic \& Bradlow, 2007).

위의 다양한 연구 결과에서 알 수 있듯이 클리어스피치는 효 과적인 의사소통 전략이지만 국내에서는 거의 적용되고 있지 않는 실정이다. 따라서 본 종설에서는 클리어스피치의 발성 방 법, 일반 발성법과의 음향학적 차이 비교, 어음인지도 향상 효 과에 대한 선행 연구들을 분석하여, 한국형 클리어스피치의 적 용을 위한 기초 지식을 제공하고자 한다.

\section{METHODS AND RESULTS}

\section{클리어스피치 발성법}

클리어스피치의 발성법은 많은 연구자들에 의해 다양한 방 법으로 제시되고 있는데, 선행연구에서 제안되었던 발성법들을 Table 1에 제시하였다. 일부 연구자들은 일반 발성법은 발성 시 에 따로 주의나 노력을 기울이지 않고 자연스럽게 발성하는데 반해 클리어스피치의 발성법은 정확한 발성에 주의를 기울이면 서 명확하게 발음하는 노력이 동반된다고 보고하였다(Bradlow et al., 2003; Ferguson, 2004; Godoy et al., 2014; Helfer, 1998; Picheny et al., 1985). 또한 일반 발성법에 비해 입모양을 크게 만든 후 발음해야 한다고 제시하고 있다(Godoy et al., 2014; Smiljanic \& Bradlow, 2007). 하지만 너무 과도하게 입모 양을 크게 하여 발음하면 시각적 입력 정보와 청각적 입력 정 보 간의 혼란으로 인하여 오히려 어음인지도의 저하를 가져올 수도 있기 때문에 턱 관절에 무리하게 힘이 들어가지 않는 범위 에서 발성하도록 제안하고 있다(Tye-Murray, 2004). 그리고 주 요 문구를 강조해서 발음해야 하는데, 특히 명사, 동사, 형용사를 강조해야 한다고 제시하고 있다(Caissie et al., 2005; Picheny et al., 1985; Tye-Murray, 2004). 전체 말 속도는 일반 발성법보다 느리게 발음해야 하고, 주요 문구나 절 사이에는 휴지기를 유지 해야 한다고 제시하고 있다(Godoy et al., 2014; Kricos, 2006; Smiljanic \& Bradlow, 2007; Tye-Murray, 2004; Uchanski et al., 1996). 또한 목소리는 생동감 있게 유지하면서 말끝을 흐리 지 않는 것이 주요 방법이라고 제시하였다(Helfer, 1998; Kricos, 2006; Picheny et al., 1985).

\section{클리어스피치의 음향학적 특성}

클리어스피치는 일반 발성법과는 다른 음향학적 특징을 보인 다. 첫째, 클리어스피치는 일반 발성법에 비해 증가된 장기평균 어음스펙트럼(long-term average speech spectrum)을 보인다. 특히 중주파수 대역인 $1,000 \mathrm{~Hz}$ 와 $3,000 \mathrm{~Hz}$ 사이의 장기평균어 음스펙트럼의 에너지 증가가 두드러지는 것으로 보고되고 있다 (Krause \& Braida, 2004). 둘째, 클리어스피치는 주파수와 강도 에 따른 진폭의 변화가 일반 발성법에 비해 크다. 일반적으로 문장의 인지도에서는 $4 \mathrm{~Hz}$ 와 $16 \mathrm{~Hz}$ 사이의 진폭변조가 중요한 역할을 하며, 음소의 식별에서는 $2 \mathrm{~Hz}$ 이하에서의 진폭변조가 중요한 역할을 한다(Drullman et al., 1994a; Drullman et al.,

Table 1. Summary of production methods for clear speech

Production methods
Speaking to a hearing impaired listener or a non-native speaker or
in a noisy environment
Articulate (vocal) effort than in conversational speech
Exaggerated speech movements
Place stress on the adjectives, noun, and verbs (key words)
Slow speech rate just a bit
Uses frequent pauses (slight pauses are used between phrases and
thoughts)
Strives to maintain a lively voice
Avoid slurring words together

\section{References}

Bradlow et al., 2003; Ferguson, 2004; Godoy et al., 2014; Helfer, 1998; Picheny et al., 1985

Helfer, 1998; Picheny et al., 1985

Caissie et al., 2005; Helfer, 1998; Kricos, 2006; Picheny et al., 1985; Tye-Murray, 2004

Godoy et al., 2014; Smiljanic \& Bradlow, 2007

Caissie et al., 2005; Picheny et al., 1985; Tye-Murray, 2004

Godoy et al., 2014; Smiljanic \& Bradlow, 2007; Tye-Murray, 2004; Uchanski et al., 1996

Kricos, 2006; Tye-Murray, 2004

Kricos, 2006

Helfer, 1998; Kricos, 2006; Picheny et al., 1985 
1994b). 클리어스피치는 모든 옥타브 밴드에서 $3 \sim 4 \mathrm{~Hz}$ 까지의 변조 주파수(modulation frequency)에 대해 일반 발성법보다 더 큰 변조 깊이(modulation depth)를 가진다(Krause \& Braida, 2004). 이것은 클리어스피치의 시간축포락선(temporal envelope)이 더욱 크게 증폭된 것을 의미하기 때문에 어음인지 도의 향상에 기여할 수 있다고 보고하였다(Amano-Kusumoto \& Hosom, 2011). 셋째, 클리어스피치는 모음의 확장성(vowel expansion)이 두드러진다. 영어의 모음 발성에서 일반 발성법과 클리어스피치를 비교했을 때 클리어스피치에서의 모음축약현 상이 일반 발성법보다 현저하게 줄어든 것으로 나타났다(Moon \& Lindblom, 1994). Chen(1980)의 연구결과에서도 클리어스피 치의 긴장모음(tense vowels)이 동일한 모음을 여러 번 발성하 여 제1포먼트(F1)와 제2포먼트(F2)의 주파수 분산 범위를 분석 하였을 때, 일반 발성법에 비해 더 밀접하게 분포되었으며 모음 에 따라 명확한 위치에 분포되었고 더 넓은 모음 삼각도를 가지 는 것으로 관찰되었다. 또한 한국어의 격음(aspirated)과 연폐 쇄음(lenis stop)을 구분할 때 두음의 기본 주파수(fundamental frequency, F0)의 차이가 클수록 두 말소리를 명확하게 구분할 수 있는데, 일반 발성법보다 클리어스피치로 두음을 발성했을 때 FO의 차이가 큰 것으로 나타났다(Kang \& Guion, 2008). 넷 째, 클리어스피치는 일반 발성법에 비해 느린 말 속도(speech rate)로 발성된다. 말 속도가 느려지는 데에는 다양한 이유가 있 을 수 있지만 대표적으로는 모음지속시간(vowel duration)이 증가하고 공간이 확장되며 짧은 휴지기가 빈번하게 나타나기 때문인 것으로 보고하고 있다(Amano-Kusumoto \& Hosom, 2011; Bradlow et al., 2003; Godoy et al., 2014; Picheny et al., 1986). 영어를 기준으로 클리어스피치는 일반 발성법에 비해 약 2배 정도 느린 말 속도로 발성된다(Picheny et al., 1986). 말 속 도가 어음인지도에 미치는 영향을 알아보기 위해 평균적으로 분당 글자수(words per minute, wpm)가 $100 \mathrm{wpm}$ 인 클리어스 피치 문장을 일반 발성법과 같은 속도인 $200 \mathrm{wpm}$ 으로 균일하 게 시간압축(time-compressed)하여 어음인지도의 변화를 측 정하였을 때 점수의 변화는 평균적으로 $75 \%$ 에서 약 $45 \%$ 로, 어 음인지도 수행력이 저하되었다(Picheny et al., 1989). 이 연구 결 과에서 알 수 있듯이 비록 말 속도가 클리어스피치의 어음인지 도 향상의 모든 부분을 설명해 주지는 못하지만 부분적으로 기여하고 있음을 알 수 있다. 다섯째, 클리어스피치는 자음에너 지의 증가와 발성시간에 따른 자모음비(consonant to vowel ratio, CVR)의 증가가 두드러진다. 클리어스피치가 일반 발성법 보다 자모음 $(\mathrm{CV})$ 인지에 있어서 무성자음일 때 발음을 위해서 닫힌 입이 열리는 순간부터 성대의 진동이 개시되기까지의 시 간인 성대진동 시작시간(voice onset time)이 더 길고, 자모음 비율이 더 높게 나타났다(Chen, 1980). 또 다른 연구에서 자모
음강도 비율(consonant-to-vowel intensity ratios, CVR)은 남 성의 경우에는 일반 발성법에서 $-4.73 \mathrm{~dB}$ CVR로 나타났으나 클리어스피치의 경우에는 $-3.46 \mathrm{~dB} C V R$ 로 나타났고, 여성의 경우에는 일반 발성법에서 $-10.09 \mathrm{~dB}$ CVR로 나타났으나, 클리 어스피치에서 $-8.34 \mathrm{~dB}$ CVR로 나타나 남녀 모두 자모음강도 비율이 증가하였고, 남성보다 여성의 경우에 더 크게 증가하였 다(Bradlow et al., 2003). 선행 연구들의 결과를 종합해 보면 클 리어스피치는 일반 발성법과는 뚜렷한 음향학적 차이를 가지고 있음을 알 수 있고, 하나의 특징이 전체 어음인지도의 향상에 기여하는 것이 아니라 여러 요소가 결합하여 종합적인 어음인 지도의 향상에 기여하고 있음을 알 수 있다.

\section{클리어스피치의 어음인지도 향상 효과}

클리어스피치는 어음인지도 향상을 위한 효과적인 의사소통 전략으로 알려져 있다(Payton et al., 1994; Picheny et al., 1985; Uchanski, 1988). 클리어스피치의 사용은 건청성인 및 아동의 어음인지도 향상에 기여할 수 있다. 건청인을 대상으로 3 명의 화자에 의해 녹음된 consonant-vowel (CV) 음소를 소음하에 서 제시하였을 때, 클리어스피치가 일반 발성법보다 약 $22 \%$ 의 어음인지도 향상 효과가 있는 것으로 나타났다(Chen, 1980). 또한 $5 \mathrm{~dB}$ signal-to-noise ratio (SNR)의 신호대잡음비 상황에 서 클리어스피치의 사용은 건청성인의 경우에 약 $15 \%$ 에서 $20 \%$ 정도 어음인지도가 개선되는 것으로 나타났다(Uchanski, 2005). Bradlow et al.(2003)의 연구에서는 학습장애가 있는 아 동 63 명과 건청아동 36 명을 소음하 환경에서 일반 발성법과 클 리어스피치를 사용하여 어음인지도 평가를 실시했을 때, 클리 어스피치를 신호음으로 제시한 경우에 정상아동 그룹의 경우 에는 $8.8 \%$, 학습장애아동 그룹의 경우에는 $9.2 \%$ 의 어음인지도 향상 효과가 나타나는 것으로 보고하고 있다. 또한 클리어스피 치는 난청인의 어음인지도 향상에도 도움을 줄 수 있다. Picheny et al.(1985)의 연구에 의하면 3명의 화자에 의해 녹음된 무의미 문장을 감각신경성 난청인에게 들려주었을 때 클리어스 피치로 문장을 제시한 경우에 일반 발성법으로 제시한 경우보 다 약 $17 \%$ 정도 더 높은 어음인지도 점수를 보이는 것으로 나 타났다. 또한 클리어스피치는 소음 속에서의 어음인지도 향상 에도 기여하는 것으로 보인다. Payton et al.(1994)의 연구에 의 하면 10 명의 건청인과 2 명 난청인을 대상으로 무의미 문장을 사 용하여 무잔향음(anechoic) 환경, 거실(living room) 환경, 회의 실(conference room) 환경의 3종류 환경음과 어음소음(speechshaped noise), 백색소음(analog white noise)의 신호대잡음비 율을 4종류로 혼합하여 제시하였을 때, 어음인지도의 향상은 건청인의 경우에는 약 $20 \%$, 난청인의 경우에는 약 $26 \%$ 로 일반 발성법을 사용했을 때보다 클리어스피치를 사용하였을 때 어 
음인지도가 향상됨을 확인하였다. 게다가 클리어스피치는 원어 민 및 비원어민을 대상으로 한 연구에서도 어음인지도의 향상 이 확인되었다. 예를 들어 영어 원어민 4 명의 화자와 영어수행 력이 높은 크로아티아인 16 명의 건청인을 대상으로 의미론적 변칙문장을 사용하여 $+5 \mathrm{~dB} \mathrm{SNR}$ 의 소음을 제시한 환경에서 어음인지도를 측정한 결과, 일반 발성법 사용의 경우에는 약 $54 \%$, 클리어스피치 사용의 경우에는 약 $70 \%$ 로 두 발성법에 따 른 어음인지도 점수의 차이는 유의미한 것으로 나타났다. 그리 고 동일 연구에서 영어가 유창한 크로아티아인 화자와 영어 원 어민 청자를 대상으로 $0 \mathrm{~dB} \mathrm{SNR}$ 상황에서 어음인지도를 비교 한 결과 일반 발성법의 경우에는 약 $31 \%$ 의 어음인지도를 보였 으나, 클리어스피치의 경우에는 약 $41 \%$ 의 어음인지도를 보여 발성법에 따른 어음인지도의 유의미한 차이를 확인할 수 있었 다. 또한 영어가 유창한 크로아티아인 화자와 영어 수행력이 높 은 크로아티아인 건청인을 대상으로 $+5 \mathrm{~dB}$ SNR 상황에서 어 음인지도를 측정한 결과, 일반 발성법 사용의 경우에는 약 $49 \%$, 클리어스피치 사용의 경우에는 약 $62 \%$ 로 두 발성법에 따른 어 음인지도의 유의미한 차이가 나타나는 것으로 보고하였다. 위 세 번의 실험은 원어민과 비원어민 청자들 사이에서 원어민의 클리어스피치가 비원어민 클리어스피치보다 더 높은 어음인지 도 수행력을 보여주었으며, 이 연구 결과는 클리어스피치가 원 어민과 비원어민 청자와 화자에 상관없이 어음인지도에 효과가 있는 조음방식임을 보여준다고 할 수 있다(Smiljanic \& Bradlow, 2007). 선행 연구들의 결과에서 알 수 있듯이, 클리어스피 치의 사용은 건청성인 및 아동, 난청인, 원어민 및 비원어민에 게 어음인지도 수행력 향상에 효과가 있는 것으로 볼 수 있다. 또한 클리어스피치의 사용은 소음 환경에서도 어음인지도 향 상에 효과가 있음을 알 수 있다.

\section{DISCUSSIONS}

본문의 내용을 정리하면, 클리어스피치는 일반 발성법과는 다른 음향학적인 특성을 나타내는 발성법을 사용하며, 건청성 인 및 아동, 난청인, 비원어민의 어음인지도 수행력 향상에 기여 함은 물론, 소음 환경에서도 청취수행력을 향상시킬 수 있는 화 자 중심의 의사소통 전략법이다. 그러나 대부분의 클리어스피 치의 효과는 영어를 기반으로 증명되어 음향학적 특성이 다른 한국어 기반 클리어스피치를 국내에 도입하기에는 추가적인 연 구가 필요하다고 할 수 있다. 따라서 효과적인 한국형 클리어스 피치의 적용을 위한 향후 연구 방향에 대한 몇 가지 제언을 하 고자 한다.

\section{한국어 기반 클리어스피치의 음향학적 특성 분석의 필요성}

영어는 한국어와 언어적 및 음향적 특성이 다르다. 예를 들 어 한국어와 영어는 분절음의 특성 차이가 두드러진다. 한국어 에는 영어에 없는 거센소리(/ㅋ/, /E/, /피/, /ㅊ/)와 된소리//T//, /匹/, /삐/, /ㅆ/, /ㅉ//)가 존재한다. 물론 영어 자음 중 무성 폐쇄 음 $(/ \mathrm{p} /, / \mathrm{t} /, / \mathrm{k} /)$ 이 존재하지만, 한국어에서 /p/는 /ㅂ/, /표/, /삐/

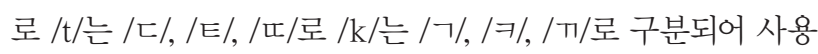
되므로 두 언어의 분절적 특성은 분명한 차이가 있다고 할 수 있다. 반면 영어에 존재하는 /f/, /v/, /J/, / / / /, /3/,/J/, /dz/와 같 은 발음은 한국어에는 존재하지 않는 분절음들이며, 한국어 분 절인 /리은 영어에서 / $/ /$ 과 $/ \mathrm{r} /$ 두 가지 이음으로 나뉘어 발성 된다(Chong, 1984). 각 분절음은 음성에너지가 집중되어 있는 주파수영역이 존재하는데, 두 언어 간 음소 분포가 다르다면 주 파수별 에너지 분포도가 다를 수 있다(Lee et al., 2005). 이를 반 영하듯, 한국어, 중국어, 영어의 어음역동범위(speech dynamic range)를 비교한 Jin et al.(2014)의 연구 결과에서 보면 영어와 한국어는 다른 주파수별 역동범위를 갖고 있음을 확인할 수 있 다. 두 언어 간 언어적인 특성은 음절구조에서도 찾아볼 수 있 다. 음절구조적인 관점에서 두 언어를 구분하면 한국어는 음절 중심 언어(syllable-based language)이고, 영어는 강세 중심 언 어(stress-based language)이다. 음절 구조는 한국어의 경우에 는 자음-모음-자음(consonant-vowel-consonant, $\mathrm{CVC}$ )이 기 본형으로 사용되고 때에 따라서 CV (예: / 가/) 또는 V (예: /아/) 형태로 사용되어 자모음비가 비슷하게 유지되는 반면에, 영어의 경우에는 'street'과 'glimpsed'처럼 자음의 비율이 높아질 수 있 는 특성이 있다(Chong, 1984).

위에서 언급한 차이 외에도 두 언어는 언어적 및 음향적인 다양한 차이를 가지고 있어 한국형 클리어스피치의 효과를 검 증하기 앞서 음향적인 특성 분석이 선행되어야 할 것이다. 특히 어음인지도 향상에 직접적인 기여도가 증명된 말 속도, 장기평 균어음스펙트럼, 시간축포락선과 같은 특성들이 한국어 기반 클리어스피치에서도 나타나는지 확인할 필요가 있다. 만약 영 어의 클리어스피치에서 나타난 음향적인 특성이 한국어 기반 클리어스피치에서도 나타난다면, 다양한 대상군(난청인 및 건 청인)에 대한 어음인지도 향상 효과를 측정해 볼 수 있을 것이 다. 그리고 한국어 기반 클리어스피치의 어음인지도 향상 효과 가 증명된다면, 한국형 클리어스피치 훈련법은 효과적인 화자 중심 의사소통 전략으로서 적용될 수 있을 것이다.

\section{한국형 클리어스피치 훈련프로그램 개발의 필요성}

일반적으로 클리어스피치는 훈련(training)을 통해 발성법을 습득할 수 있다. Tye-Murray \& Witt(1997)의 의사소통 전략훈 련에 근거하여 Caissie et al.(2005)은 형식적 설명(formal in- 
struction), 안내 학습(guided learning), 실전 연습(real-world practice)의 3단계로 구성하는 클리어스피치 훈련법을 제시하 였다. 형식적 설명은 효과적인 듣기와 말하기, 수정 전략에 대 하여 안내하는 절차를 말한다. 예를 들어, 발화 속도를 평소보 다 늦추고 중요 단어를 강조하며 주요 단어 앞에서 휴지기를 갖는 클리어스피치와 일반 발성법 간의 차이에 대한 설명이 이 단계의 주요한 내용이다. 안내 학습에서는 시나리오 또는 담화 문 등을 이용하여 클리어스피치 발성법의 안내를 받으면서 발성 연습을 하는 훈련이 주된 내용이다. 실전 연습은 가정 등에서 클리어스피치를 사용하여 자연스런 대화를 시도하면서 화자는 발성법을 숙달하고 청자는 클리어스피치 청취에 대한 적응력을 향상시키는 내용을 담고 있다.

선행 연구들에 근거했을 때, 클리어스피치는 단순한 안내보 다는 훈련을 통해 발성법을 습득하였을 때 그 효과가 더욱 증 가하는 것으로 보인다. Caissie et al.(2005)는 두 명의 난청인 배 우자를 대상으로, 한 명은 클리어스피치에 대해 간단히 안내만 하였고, 다른 대상자에게는 클리어스피치 습득에 적극 개입하 여 한 달 동안 훈련을 실시한 후에 클리어스피치를 각각 녹음 하여 난청인 및 건청인을 대상으로 어음인지도를 측정하였다. 그 결과, 클리어스피치 훈련을 받은 대상자의 목소리로 측정한 어음인지도가 안내만 받은 대상자에 비해 난청인 및 건청인 그 룹 모두에서 약 $9 \%$ 정도 더 높은 어음인지도를 보이는 것으로 나타났다. 선행 연구의 결과에서 알 수 있듯이 클리어스피치의 효과를 증진시키기 위해서는 단순한 안내보다는 체계적인 훈 련법의 개발이 필요하다.

영어 기반 클리어스피치의 훈련법 중 하나는 다음과 같았다. Caissie et al.(2005)은 난청인 배우자를 위한 클리어스피치 발 성에 관한 훈련 지침을 포함한 프로그램을 제시하였다. 적극적 개입 방법으로는 핵심 단어에 줄을 긋고 자연스러운 휴지기를 표시하며 피드백을 통해 발성법에 대한 개념을 확립하도록 하 였다. 발성법에 대한 개념이 확립되면 문장 수준에서 읽기 연습 을 진행하였고, 문장 단위에서 클리어스피치 발성법이 자연스 러워지면 담화 수준에서 발성법을 연습하도록 프로그램을 구성 하였다. 이때도 전문가의 지속적인 피드백을 제공함으로써 발성 법을 습득할 수 있도록 하였다. 그리고 책자나 대화 샘플 자료를 난청인 배우자에게 제공하여 가정에서는 난청인 대상자와 클리 어스피치를 실제로 연습할 수 있도록 프로그램을 구성하였다. 정리하면, 처음에는 클리어스피치 발성법에 대한 지식을 습득 하고 그 후에는 문장 수준에서 발성 연습을 하고, 익숙해지면 길이가 긴 담화 수준에서 자연스럽게 클리어스피치를 발성하도 록 연습하는 과정으로 진행하고, 가정에서 실전연습을 통해 숙 달하는 과정으로 프로그램을 구성하고 있음을 알 수 있다.

영어 기반 클리어스피치는 약 15 20\% 정도의 어음인지도 향
상 효과가 증명되어 하나의 의사소통 전략으로 적용되어 사용되 고 있다(Payton et al., 1994; Picheny et al., 1985; Uchanski, 2005). 한국에서는 청자 중심 청능재활은 활발히 이루어지고 있 으나 화자 중심 의사소통 전략은 보편적으로 적용되고 있지 않 은 실정이다(Kim \& Bahng, 2017; Kim \& Lee, 2017). 한국어 기반 클리어스피치의 효과가 검증되고 체계적인 훈련법이 개발 된다면 난청인의 의사소통 능력 향상에 기여할 수 있는 효과적 인 화자 중심 의사소통 전략으로 적용될 수 있을 것이다.

중심 단어 : 어음인지도·클리어스피치·의사소통전략.

\section{Acknowledgments}

이 논문은 2016년도 정부(미래창조과학부)의 재원으로 한국연구 재단의 지원을 받아 수행된 기초연구사업임(NRF-2015R1C1A1A010 52458).

\section{REFERENCES}

Amano-Kusumoto, A. \& Hosom, J. P. (2011). A Review of Research on Speech Intelligibility and Correlations with Acoustic Features. Technical Report CSLU-011-001. (pp. 1-16). Beaverton, OR: Oregon Health \& Science University.

Bilbao, S. C. B. (2013). Perception of natural and enhanced non-native contrasts in clear speech. Onomázein: Revista de Lingüística, Filología y Traducción de la Pontificia Universidad Católica de Chile, (27), 207-219.

Bradlow, A. R. \& Bent, T. (2002). The clear speech effect for non-native listeners. The Journal of the Acoustical Society of America, 112(1), 272-284.

Bradlow, A. R., Kraus, N., \& Hayes, E. (2003). Speaking clearly for children with learning disabilities: Sentence perception in noise. Journal of Speech, Language, and Hearing Research, 46(1), 80-97.

Caissie, R., McNuttn Campbell, M., Frenette, W. L., Scott, L., Howell, I., \& Roy, A. (2005). Clear speech for adults with a hearing loss: Does intervention with communication partners make a difference? Journal of the American Academy of Audiology, 16(3), 157-171.

Caissie, R. \& Tranquilla, M. (2010). Enhancing conversational fluency: Training conversation partners in the use of clear speech and other strategies. Seminars in Hearing, 31(2), 95-103.

Chen, F. R. (1980). Acoustic characteristics and intelligibility of clear and conversational speech at the segmental level (master's thesis). Massachusetts Institute of Technology, Cambridge, MA.

Chong, H. J. (1984). A contrastive analysis of English and Korean (master's thesis). Ball state University, Department of English, Muncie, IN.

Drullman, R., Festen, J. M., \& Plomp, R. (1994a). Effect of reducing slow temporal modulations on speech reception. The Journal of the Acoustical Society of America, 95(5), 2670-2680.

Drullman, R., Festen, J. M., \& Plomp, R. (1994b). Effect of temporal envelope smearing on speech reception. The Journal of the Acoustical Society of America, 95(2), 1053-1064.

Ferguson, S. H. (2004). Talker differences in clear and conversational speech: Vowel intelligibility for normal-hearing listeners. The Journal of the Acoustical Society of America, 116(4), 2365-2373.

Gagné, J. P., Masterson, V., Munhall, K. G., Bilida, N., \& Querengesser, C. (1994). Across talker variability in auditory, visual, and audiovisual speech intelligibility for conversational and clear speech. Journal of the Academy of Rehabilitative Audiology, 27, 135-158.

Godoy, E., Koutsogiannaki, M., \& Stylianou, Y. (2014). Approaching speech intelligibility enhancement with inspiration from Lombard and clear speaking styles. Computer Speech and Language, 28(2), 629647.

Helfer, K. S. (1998). Auditory and auditory-visual recognition of clear and 
conversational speech by older adults. Journal of the American Academy of Audiology, 9(3), 234-242.

Jin, I. K., Kates, J. M., \& Arehart, K. H. (2014). Dynamic range for speech materials in Korean, English, and Mandarin: A cross-language comparison. Journal of Speech, Language, and Hearing Research, 57(5), 20242030.

Kang, K. H. \& Guion, S. G. (2008). Clear speech production of Korean stops: Changing phonetic targets and enhancement strategies. The Journal of the Acoustical Society of America, 124(6), 3909-3917.

Kim, J. \& Lee, K. (2017). Effects on word and sentence recognition by auditory training using environmental sound for elderly hearing impaired. Audiology and Speech Research, 13(2), 115-122.

Kim, N. K. \& Bahng, J. (2017). Development of a story based auditory training tool and evaluation of the training efficacy for adult hearing impaired listeners. Audiology and Speech Research, 13(2), 133-140.

Krause, J. C. \& Braida, L. D. (2004). Acoustic properties of naturally produced clear speech at normal speaking rates. The Journal of the Acoustical Society of America, 115(1), 362-378.

Kricos, P. B. (2006). Audiologic management of older adults with hearing loss and compromised cognitive/psychoacoustic auditory processing capabilities. Trends in Amplification, 10(1), 1-28.

Lee, J. H., Jang, H. S., \& Chung, H. J. (2005). A study on frequency characteristics of Korean phonemes. Audiology, 1(1), 59-66.

Liu, S., Del Rio, E., Bradlow, A. R., \& Zeng, F. G. (2004). Clear speech perception in acoustic and electric hearing. The Journal of the Acoustical Society of America, 116(4), 2374-2383.

Moon, S. J. \& Lindblom, B. (1994). Interaction between duration, context, and speaking style in English stressed vowels. The Journal of the Acoustical society of America, 96(1), 40-55.

Payton, K. L., Uchanski, R. M., \& Braida, L. D. (1994). Intelligibility of conversational and clear speech in noise and reverberation for listeners with normal and impaired hearing. The Journal of the Acoustical Society of America, 95(3), 1581-1592.

Picheny, M. A., Durlach, N. I., \& Braida, L. D. (1985). Speaking clearly for the hard of hearing I: Intelligibility differences between clear and conversational speech. Journal of Speech, Language, and Hearing Research, 28(1), 96-103.
Picheny, M. A., Durlach, N. I., \& Braida, L. D. (1986). Speaking clearly for the hard of hearing II: Acoustic characteristics of clear and conversational speech. Journal of Speech, Language, and Hearing Research, 29(4), 434-446.

Picheny, M. A., Durlach, N. I., \& Braida, L. D. (1989). Speaking clearly for the hard of hearing III: An attempt to determine the contribution of speaking rate to differences in intelligibility between clear and conversational speech. Journal of Speech, Language, and Hearing Research, 32(3), 600-603.

Schum, D. J. (1996). Intelligibility of clear and conversational speech of young and elderly talkers. Journal of the American Academy of Audiology, 7(3), 212-218.

Smiljanic, R. \& Bradlow, A. (2007). Proceedings from the 16th International Congress of Phonetic Sciences: Clear Speech Intelligibility: Listener and Talker Effects (pp. 661-664). Saarbrücken, Germany.

Snidecor, J. C., Malbry, S. A., \& Hearsey, E. L. (1944). Methods of Training Talkers for Increasing Intelligibility in Noise (ORSD Report 3178). New York, NY: The Psychological Corporation.

Tolhurst, G. C. (1957). Effects of duration and articulation changes on intelligibility, word reception and listener preference. Journal of Speech and Hearing Disorders, 22(3), 328-334.

Tye-Murray, N. (2004). Foundations of Aural Rehabilitation: Children, Adults, and Their Family Members. (2nd ed). New York, NY: ThomsonDelmar Learning.

Tye-Murray, N. \& Witt, S. (1997). Communication strategies training. Seminars in Hearing, 18(2), 153-164.

Uchanski, R. M. (1988). Spectral and temporal contributions to speech clarity for hearing impaired listeners (master's thesis). Massachusetts Institute of Technology Research, Laboratory of Electronics, Cambridge, MA.

Uchanski, R. M. (2005). Clear Speech. In D. B. Pisoni \& R. M. Remez. Handbook of Speech Perception. (pp. 207-235). Malden, MA: Blackwell Publishers.

Uchanski, R. M., Choi, S. S., Braida, L. D., Reed, C. M., \& Durlach, N. I. (1996). Speaking clearly for the hard of hearing IV: Further studies of the role of speaking rate. Journal of Speech, Language, and Hearing Research, 39(3), 494-509. 